\title{
Acoustic demands and influencing factors in facilities for the elderly
}

\author{
Luying Wang a and Jian Kang b,* \\ ${ }^{a}$ Key Laboratory of Cold Region Urban and Rural Human Settlement Environment Science and Technology, Ministry of \\ Industry and Information Technology, School of Architecture, Harbin Institute of Technology, 150001, 66 West Dazhi Street, \\ Nan Gang District, Harbin, China \\ ${ }^{b}$ UCL Institute for Environmental Design and Engineering, University College London (UCL), London, WC1H ONN, United
} Kingdom

${ }^{*}$ Corresponding Author

\begin{abstract}
The aim of this study was to examine the characteristics of the elderly individuals' acoustic demands and the effects of six influencing factors, categorized into the following three types: activity type, objective environment (number of people in a room, sound pressure level), and demographic factors (age, sex, and occupation type). In addition, we sought to identify relationships between sound preference and acoustic demands. The study was based on a semi-structured interview survey and objective measurements recorded in six facilities for the elderly in China. The results suggested that almost half of the interviewees chose not to add or abate any sound. For the remaining participants, the addition of mainly soothing music to the environment was required, indicating a considerable preference for it over natural sounds, stimulating music, and other sounds. Activity type was an important factor influencing acoustic demands, in that playing ball games and sitting still tended to engender demands for the addition of sounds, while people who were playing or watching Chinese chess did not wish to hear any sounds including soothing music. An analysis of the number of people in a room showed that if that number reached 12, demands for the abatement of sounds increased sharply, particularly for the sound of people talking. In addition, sound pressure level, age, sex, and occupation type (mental or physical work) influenced the demand for acoustic abatement, which involved the abatement of the sound of people talking or other noises and 'no need to abate'. Natural sounds were seldom required during most activities, with the exception of chatting and sitting still, which is inconsistent with the extent to which people enjoy such sounds. However, there was a significant positive correlation between the elderly individuals' preference for the overall acoustic environment and their demands for the addition of natural sounds. Furthermore, women were more likely to demand the addition of natural sounds, relative to men.
\end{abstract}

Keywords: acoustic demands; activity type; elderly; influencing factor; subjective survey

2020 Applied Acoustics

Date Received: 22 August 2019

Date Received in revised form: 27 May 2020

Date Accepted: 2 June 2020 


\section{Introduction}

China has the largest population of elderly people in the world, and this continues to grow [1]. Consequently, facilities for the elderly in China have expanded rapidly. The national regulations regarding these facilities stipulate a quiet environment; however, most lack professional acoustic design. Although older adults have reported the lowest level of annoyance with environmental noise [2], their acoustic demands are important.

Early in 1974, in a systematic review, Miller mentioned that listening comprehension in complex environments appears to begin to deteriorate at the age of approximately 30 years and declines steadily thereafter. Generally, older listeners require lower background noise, relative to younger individuals, for practical, satisfactory communication [3]. Likorotky concluded that people become less sensitive to high frequencies and low voice volume with age [4]. Moreover, Kim and Soeta studied different responses to public address systems between young and elderly people on subway platforms, and older people showed worse speech intelligibility relative to younger people [5]. Moreover, in quantitative experiments, $\mathrm{Wu}$ and Bentler found that older people reported quieter lifestyles relative to those of younger people [6]. However, hearing loss was shown to affect motor capability in older adults and increase the risk of falls [7], indicating that the acoustic environment in living spaces is far more critical than it often seems.

Studies examining soundscape, including sound level evaluation [8-9], subjective acoustic comfort [10-12], and sound preference [13-15], have been conducted for almost two decades. The effects of various demographic factors have been examined widely, and some studies have shown effects of age, whereas few have observed important effects of sex [16]. Regarding occupation and educational level, Yu and Kang reported that people with higher educational levels showed less noise tolerance in open spaces in urban areas, relative to those with lower educational levels, and occupation was highly correlated with education [18]. However, in a study examining sound preference, Yang and Kang found no significant difference between various occupations [16]. In addition, the effect of sound-related activities on human behaviour has been shown to be noticed more as the number of people involved in the activities increase [12].

Moreover, effects of other factors, including the duration and frequency of visits [17], social background and auditory experience [17], sound sources [18], and physical features (e.g. temperature, humidity, and sunlight) [10,19] have been observed in some previous studies. Although reducing the sound pressure level (SPL) does not always change the perception of soundscape positively [20], the perception of sound has been associated with background noise [21]. In addition, the effect of crowd density on acoustic comfort in indoor spaces has been examined in recent studies [22-23]. Moreover, Aletta et al. found a positive correlation between sound levels and the numbers of people in the living rooms of nursing homes in Flanders, Belgium [24].

However, most previous studies have focused on residential areas [25-26] and open public spaces in urban areas [8,10,12-13,16-17]. In addition, although the role of age as an influencing factor has been studied extensively in both young and older adults, relatively few studies have considered only the elderly, particularly those in care facilities. Recently, some attention has been focused on acoustic environments in facilities for the elderly; however, the main content of these studies was related to objective acoustic parameters only [27].

The aim of this study was therefore to answer four main questions:

1. What are the characteristics of the elderly's acoustic demands?

2. Does what elderly people are doing affect their acoustic demands?

3. Does objective environment affect the elderly's acoustic demands?

4. Do demographic factors (i.e. age, sex, and occupation type) affect the elderly's acoustic demands?

Furthermore, we sought to answer a secondary question: can sound preference indices be utilized to estimate acoustic demands? To gain these insights and detect these factors' possible effects, a cross-sectional semi-interviewed questionnaire survey with simultaneous objective measurements of acoustic environment was carried out. This paper then briefly provides its survey methodology description and systematically explores the relationships between the selected factors as well as their effects on elderly people's acoustic demands. Finally, after delineating the main results, the paper's discussion 
section provides a preliminary exploration of the relationships between sound preference and acoustic demands as open results for future research.

\section{Methodology}

\subsection{Selection of sites}

In China, six facilities for the elderly in three cities, including two senior centres and two nursing homes in Harbin, one nursing home in Beijing, and one resort-style retirement apartment in Weihai, were selected for inclusion in the study. These three types of facility represented three typical lifestyles of the elderly in China. Senior centres are locations at which the elderly gather during the day and perform certain activities. Nursing homes are for elderly people who need nursing care and live in the facilities permanently. In addition, in recent years, resort-style retirement has become fashionable for some elderly people who wish to migrate as the seasons change, in pursuit of a comfortable temperature and new environments.

Table 1 shows the volume range of the rooms, dominating finishing materials, functional layouts, and representative indoor photos of six survey sites, with all activity rooms where most interviews occurred, filled in dark grey, since activity rooms were spaces where the elderly spend the most time during the day. In addition, the approximate volumes of these spaces range from 56 to $704 \mathrm{~m}^{3}$, and no noticeable acoustic materials have been applied to improve the indoor acoustic environment, leading to high reverberation and low speech intelligibility in the circumstance in which elderly people speak loudly and engage in activities that produce sounds simultaneously.

\subsection{Selection of variables}

In this study, acoustic demands were defined as interviewees' demands for the addition or abatement of certain sounds within the environment. Therefore, addition sound categories were selected based on previous research examining soundscapes, with particular attention paid to sound preference and acoustic comfort. Previous studies confirmed that natural sounds, as a group, are generally preferred in urban areas and elderly people are more likely to favour natural sounds, relative to younger people [10]. Therefore, natural sounds are considered a suitable sound category for 'addition' acoustic demands. Specifically, we selected the following four natural sounds frequently mentioned in soundscapes: water, birds, trees rustling, and ocean waves [10,13,16-17,28-30].

With respect to musical sounds, Huo and Ren showed that music learning in old age exerted positive and reliable effects on the maintenance and improvement of basic cognitive ability in the elderly [31]. The results of a preference test for sound types showed that elderly people's subjective preferences for the four given sound types were as follows: musical, followed by natural, human activity, and noise in decreasing preference order [32]. Therefore, we considered musical sound, including soothing and stimulating music, in the current study.

In contrast, abatement sound categories were determined according to typical sound elements that were likely to be heard in facilities for the elderly, even though they were not necessarily heard during the interviews. Accordingly, four groups of sounds (i.e. musical, activity, speech, and other sounds) were considered, with five specific sounds, including music; noise made during ball games, Mahjong, and chess; people talking; and other noises, selected.

In addition, 'no need to add' and 'no need to abate' were included in the list, to establish two baselines indicating the extent of elderly people's demands for the addition or abatement of sounds. It should be noted that all types of sound investigated in this study were listed in a specific order, to identify patterns in various sound categories including natural sounds, musical sounds, and other sounds as addition sounds and musical sounds, activity sounds, speech sounds, and other noises as abatement sounds.

\subsection{Participants}

The participants were chosen randomly, with sample sizes of 30 for senior centres and the resort-style retirement apartments and 15 for nursing homes, in which semi-structured interviews were conducted because the elderly people who 
Table 1

Basic information for six survey sites.

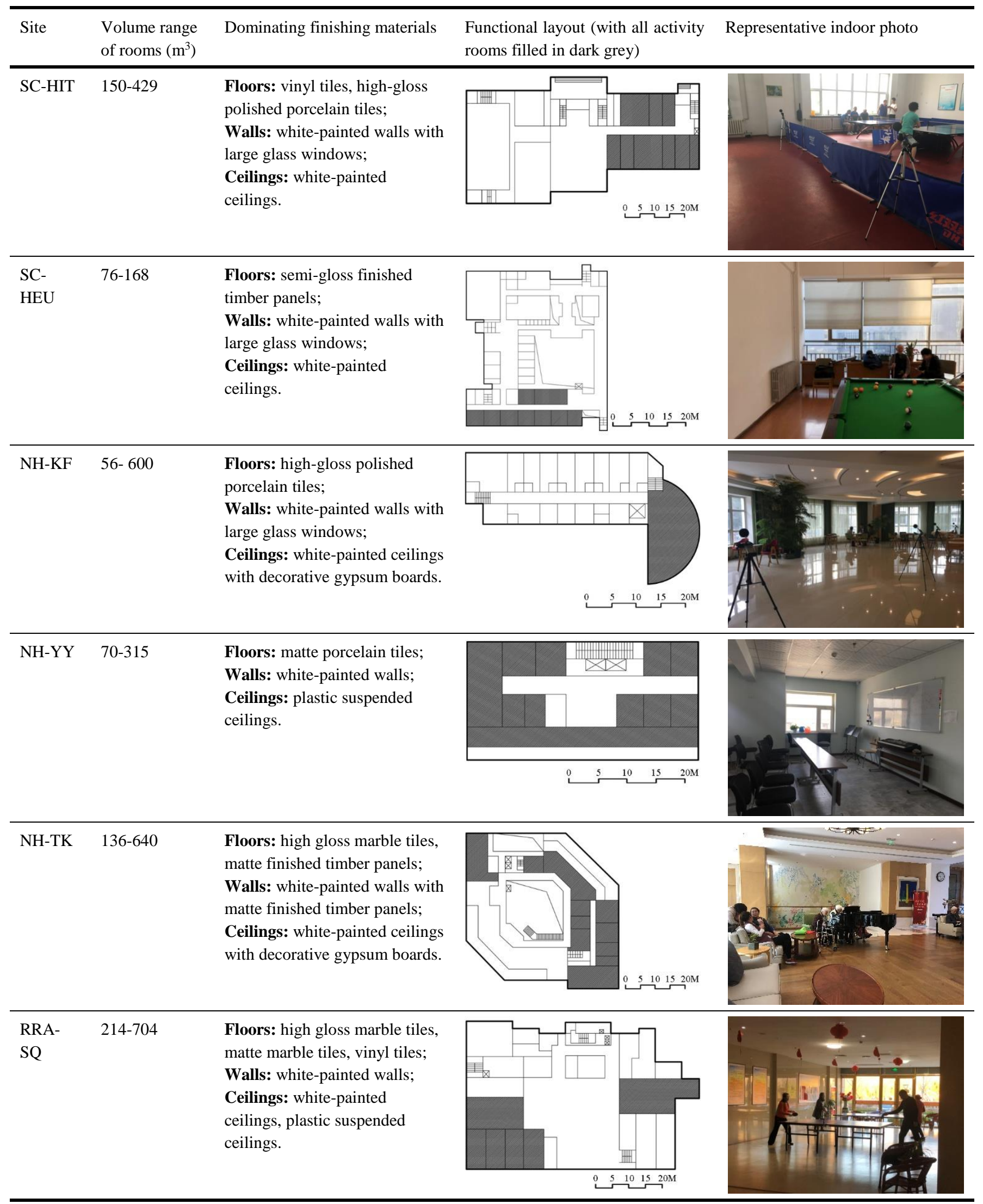

SC-HIT: Senior Centre of Harbin Institute of Technology, Harbin; SC-HEU: Senior Centre of Harbin Engineering University, Harbin; NHKF: Kaifeng Nursing Home, Harbin; NH-YY: Yiyuan Intelligent Nursing Home, Harbin; NH-TK: Taikang Nursing Home, Beijing; RRASQ: Shengquan Resort-style Retirement Apartment, Weihai. 
lived in nursing homes were older and displayed lower motion capability and greater difficulty in understanding the questions relative to the other participants. Therefore, to ensure equivalence of meaning in the questionnaire and improve the validity of the responses, semi-structured interviews were most suitable for use in nursing homes. In addition, as the acoustic demands of the elderly have not been examined systematically, semi-structured interviews could provide new insight. The sample contained at least 30 men, 30 women, 30 retired mental workers, and 30 retired physical workers, to allow analysis of differences in acoustic demands according to sex and occupation type.

\subsection{Semi-structured interview questionnaire}

A cross-sectional, semi-structured questionnaire survey was conducted at six selected sites, and 155 valid questionnaires were collected. Amongst the interviewees, $54.2 \%$ were in good hearing condition, $37.3 \%$ had partial hearing loss, and $8.5 \%$ had severe hearing loss, requiring the interviewers to speak louder. Table 2 shows the basic information for each site, and Table 3 shows the participants' age and sex distribution. The number of men was approximately equal to that of women, with some variation in age. In contrast, the distribution of the two occupation types was similar across age groups, but the sample included 103 mental workers (70.5\%) and 43 physical workers (29.5\%).

Interviewees were asked to describe what they could hear, and we evaluated their hearing loss to ensure the validity of their responses. They were then asked to choose sounds for addition and abatement from the sound categories provided. The semi-structured questionnaire pertained to the reasons why participants wished to add or abate these sounds and which other sounds they would like to add to the environment. The questionnaire also included evaluation of the likeability of the overall acoustic environment and preference for nine individual sounds corresponding to the sound categories for acoustic demands, with responses provided using a seven-point linear scale: $-3=$ dislike intensely; $-2=$ generally dislike; $-1=$ dislike slightly; $0=$ neither dislike nor like; $1=$ like slightly; $2=$ generally like; $3=$ like intensely. One-minute, Aweighted Leq (equivalent continuous sound level) and Lmax (instantaneous maximum SPL) were gathered for each interview. To avoid the influence of interview voices, the SPL values were measured immediately after the interviews. Activity type, the number of people in a room, and demographic information were also recorded after the interviews.

\section{Table 2}

Basic information for six selected sites.

\begin{tabular}{|c|c|c|c|c|c|c|c|c|}
\hline No. & Sites & Main activity types & $\begin{array}{l}\text { LAeq }(\mathrm{dB}) \\
\text { distribution } \\
(\mathrm{M} \pm \mathrm{SD})\end{array}$ & $\begin{array}{l}\operatorname{LAmax}(\mathrm{dB}) \\
(\mathrm{Max})\end{array}$ & $\begin{array}{l}\text { Age } \\
\text { distribution } \\
(\mathrm{M} \pm \mathrm{SD})\end{array}$ & $\begin{array}{l}\text { Sex ratio } \\
\text { (Men:Women) }\end{array}$ & $\begin{array}{l}\text { Occupation } \\
\text { type ratio } \\
\text { (Mental:Physical) }\end{array}$ & $\begin{array}{l}\text { The } \\
\text { number of } \\
\text { interviews }\end{array}$ \\
\hline 1 & SC-HIT, Harbin & $\begin{array}{l}\text { Table Tennis; } \\
\text { Cards and Mahjong; } \\
\text { Billiards }\end{array}$ & $67.68 \pm 5.22$ & 84.20 & $69 \pm 6.66$ & 1.85 & 3.63 & 37 \\
\hline 2 & SC-HEU, Harbin & $\begin{array}{l}\text { Table Tennis; } \\
\text { Billiards }\end{array}$ & $66.53 \pm 6.55$ & 88.20 & $74 \pm 6.66$ & 1.20 & 5.60 & 33 \\
\hline 3 & NH-KF, Harbin & $\begin{array}{l}\text { Sitting Still; } \\
\text { Cards and Mahjong }\end{array}$ & $60.21 \pm 3.86$ & 91.20 & $82 \pm 7.92$ & 0.38 & 0.82 & 22 \\
\hline 4 & NH-YY, Harbin & $\begin{array}{l}\text { Sitting Still; } \\
\text { Music-Related }\end{array}$ & $62.01 \pm 10.00$ & 85.20 & $80 \pm 7.38$ & 0.80 & 0.88 & 18 \\
\hline 5 & NH-TK, Beijing & Sitting Still & $66.01 \pm 6.64$ & 81.80 & $80 \pm 5.10$ & 0.71 & 5.00 & 12 \\
\hline 6 & RRA-SQ, Weihai & Sitting Still; Billiards & $65.08 \pm 5.80$ & 83.53 & $73 \pm 7.13$ & 1.20 & 2.20 & 34 \\
\hline
\end{tabular}

SC-HIT: HIT Senior Centre, Harbin; SC-HEU: HEU Senior Centre, Harbin; NH-KF: Kaifeng Nursing Home, Harbin; NH-YY: Yiyuan Intelligent Nursing Home, Harbin; NH-TK: Taikang Nursing Home, Beijing; RRA-SQ: Shengquan Resort-style Retirement Apartment, Weihai.

Table 3

The number of interviewees in each age group categorized by sex and occupation type.

\begin{tabular}{|c|c|c|c|c|}
\hline \multirow[t]{2}{*}{ Age group (years) } & \multicolumn{2}{|c|}{$\operatorname{Sex}(n)$} & \multicolumn{2}{|c|}{ Occupation Type (n) } \\
\hline & Women & Men & Mental workers & Physical workers \\
\hline$<60$ & 3 & 4 & 6 & 0 \\
\hline $60-70$ & 18 & 28 & 31 & 15 \\
\hline $70-80$ & 29 & 26 & 38 & 14 \\
\hline$>80$ & 25 & 19 & 28 & 14 \\
\hline Total & 75 & 77 & 103 & 43 \\
\hline
\end{tabular}




\subsection{Analysis}

SPSS 21.0 was used to establish a database with all the subjective and objective results. Multiple statistical approaches were used to analyse correlations and differences between variables. These were Pearson, Spearman, and Point-biserial correlations for factors regarding continuous and ordinal categorical variables; Chi-square correlations, one-way ANOVA and non-parametric test for factors with three or more categories of unordered categorical variables; independent samples t-test and Goodman \& Kruskal tau-y PRE for factors with two categories; and quadratic regression to determine the relationships between continuous variables.

A pre-test was conducted before the formal site survey, and the results were compared with those of formal investigation, to examine the reliability and validity of the questionnaire. Cronbach's $\alpha$ was used to test reliability, and the results were generally $>.70$ for various acoustic demand categories, indicating that the sample was sufficient and that the survey was reliable. To determine validity, construct validity was tested via factor analysis, and the results showed that three extracted factors were suitable for inclusion in the study, which matched the structure of the research and confirmed the validity of the survey.

A one-way ANOVA was performed to determine whether there was a consistent pattern in the acoustic demands of the elderly people at the three types of facility. The results indicated that three individual acoustic demands with significant differences were the addition of the sound of ocean waves (between nursing home and resort-style retirement apartment, $p=.01$ ), the abatement of the sound of people talking (between senior centre and nursing home, $p<.001$; between resortstyle retirement apartment and senior centre, $p<.01$ ), and no need to abate any sound (between senior centre and nursing home, $p<.001$; between nursing home and resort-style retirement apartment, $p=.03$ ), whereas the other 11 of 14 individual acoustic demands showed non-significant differences, suggesting that a more holistic analysis could be performed to identify the general acoustic demands of the elderly based on a wide range of ambient environments, rather than focusing on each facility type. However, the analysis regarding the addition of the sound of ocean waves, the abatement of the sound of people talking, and no need to abate any sound required caution, as discussed in Section 4.2.

Because the conditions varied between sites, examination of the effects of various factors influencing acoustic demands could be interesting. However, before analysing these effects, it is essential to develop a deeper understanding of the complex relationships between them. Various correlation analysis approaches were used for this purpose, and the results, including corresponding statistics and significance levels, are shown in Table 4. The relationships between these factors were examined pairwise. All acoustic demands were analysed according to the number of people in a room using partial correlation analysis, with activity type and age as the control variables. In addition, partial correlation analysis was performed to clarify relationships between specific activities and individual acoustic demands. To eliminate data diversity, age and sex were introduced as control variables, as activity type was strongly correlated with age, sex, the number of people, LAmax, and LAeq, however the number of people and SPL was affected by activity type.

Significance values of $p<.05$ and $p<.01$ are marked with * and $* *$, respectively.

As shown in Table 4, activity type, the number of people and LAeq were significantly correlated with most factors. However, no significant correlations between the three demographic factors (i.e. age, sex, and occupation type) were observed. With respect to correlation coefficients, $r$ values were rather low at around .20 to .40 , with the exception of that for the association between LAeq and LAmax, which were strongly positively correlated $(r=.78)$.

Overall, it is important to consider the influence of various demographic factors when analysing the effects of activity type or other factors on acoustic demands in the elderly. Regarding SPL, LAeq reflects the continuous condition in a room, while LAmax is related to sudden, loud sound, produced mainly by certain activities. Therefore, the effects of both LAeq and LAmax on acoustic demands were analysed and compared in the study. 
Table 4

Correlation coefficients $\left[\chi^{2}\right](\mathrm{F} / \mathrm{H})$ with corresponding statistics and significance.

\begin{tabular}{|c|c|c|c|c|c|c|c|}
\hline & Activity Type & The Number of people & LAeq & LAmax & Age & Sex & Occupation Type \\
\hline Activity Type & - & $(26.09) / 0.00(* *)$ & $(2.97) / 0.00(* *)$ & $(2.00) / 0.05(*)$ & $(2.78) / 0.01(* *)$ & {$[28.67] / 0.00(* *)$} & {$[13.53] / 0.10$} \\
\hline The Number of people & $(26.09) / 0.00(* *)$ & - & $0.43 / 0.00(* *)$ & $0.36 / 0.00(* *)$ & $-0.26 / 0.00(* *)$ & $0.01 / 0.93$ & $-0.08 / 0.32$ \\
\hline LAeq & $(2.97) / 0.00(* *)$ & $0.43 / 0.00(* *)$ & - & $0.78 / 0.00(* *)$ & $-0.16 / 0.06$ & $0.11 / 0.19$ & $-0.19 / 0.02(*)$ \\
\hline LAmax & $(2.00) / 0.05(*)$ & $0.36 / 0.00(* *)$ & $0.78 / 0.00(* *)$ & - & $-0.05 / 0.60$ & $0.02 / 0.82$ & $-0.11 / 0.19$ \\
\hline Age & $(2.78) / 0.01(* *)$ & $-0.26 / 0.00(* *)$ & $-0.16 / 0.06$ & $-0.05 / 0.60$ & - & $-0.13 / 0.12$ & $0.06 / 0.44$ \\
\hline Sex & {$[28.67] / 0.00(* *)$} & $0.01 / 0.93$ & $0.11 / 0.19$ & $0.02 / 0.82$ & $-0.13 / 0.12$ & - & {$[0.07] / 0.79$} \\
\hline Occupation Type & {$[13.53] / 0.10$} & $-0.08 / 0.32$ & $-0.19 / 0.02(*)$ & $-0.11 / 0.19$ & $0.06 / 0.44$ & {$[0.07] / 0.79$} & - \\
\hline
\end{tabular}

Table 4 shows correlation coefficients from Pearson, Spearman, and Point-biserial correlations, $\chi^{2}$ from chi-square test (given in square brackets), and $F / H$ from one-way ANOVA/nonparametric test (given in parentheses) between seven possible influencing factors, including activity type, the number of people in a room, equivalent SPL (LAeq), instantaneous maximum SPL (LAmax), as well as demographic variables (age, sex, and occupation type), with significance levels (two-tailed). ${ }^{\mathrm{a}}$

$* p<.05$

$* * p<.01$

${ }^{a}$ Significant results are highlighted in bold print.

\section{Results}

3.1 Basic analysis of the elderly's acoustic demands

Fig. 1 displays elderly people's acoustic demands according to the addition and abatement sound types. The results showed that elderly people with no need to add or abate any sounds accounted for approximately $40 \%$ of all interviewees. This proportion was slightly lower relative to that for the soothing music category and slightly higher relative to those for the sound of people talking and other noises, indicating that in most instances, the addition of soothing music to the environment was welcomed, and there was no need to abate any existing sounds.

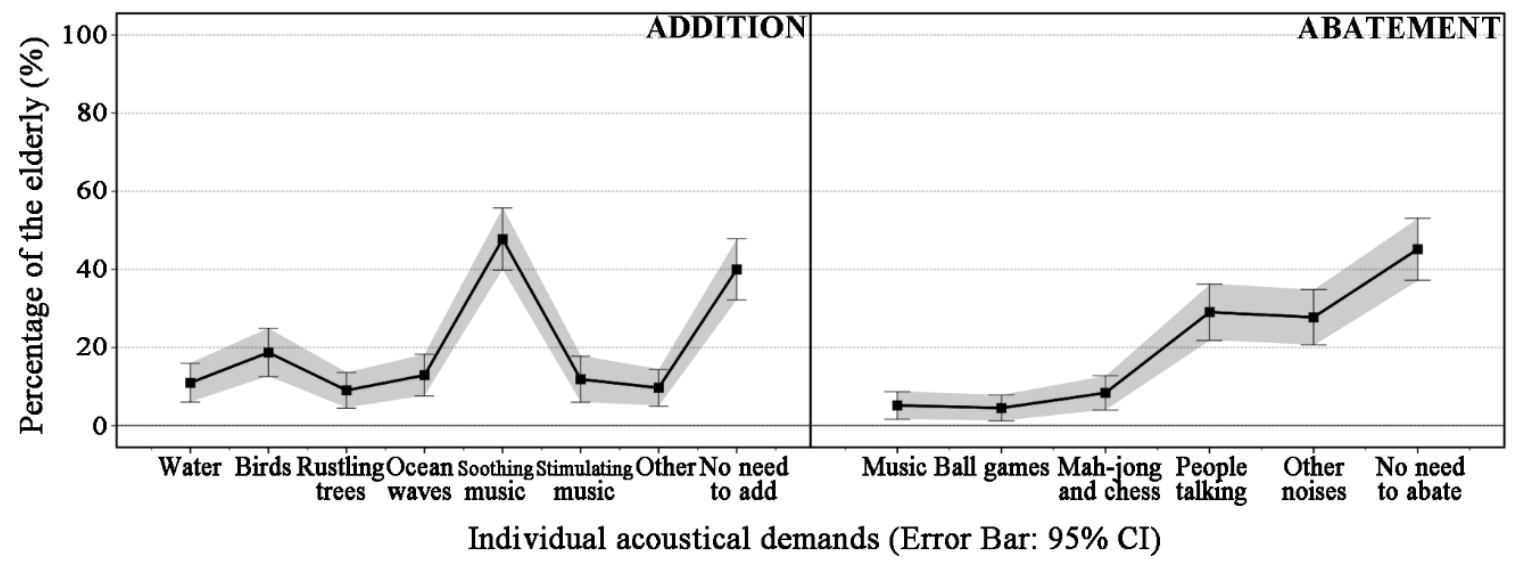

Fig. 1. The percentages of elderly people's acoustic demands according to the addition (on the left) and abatement (on the right) sound types. Error bars coloured in light grey represents $95 \%$ confidence intervals.

Aside from the 'no need to add' and 'no need to abate' categories, soothing music accounted for the largest proportion of demands (approximately 50\%). In contrast, the demand for stimulating music was considerably weaker relative to that for soothing music, even though they both belonged to the musical sound category. One possible reason for this finding was that stimulating music increases the heartrate and could cause palpitations or heart attacks in the elderly, and some elderly people mentioned this during interviews.

According to research examining urban soundscapes, increasing the richness and intensity of natural sounds could improve acoustic comfort in public open spaces in urban areas [10]. However, with respect to the acoustic demands of the 
elderly, Fig. 1 shows that the demand for four natural sound categories remained small, with proportions of participants varying from $9 \%$ to $20 \%$, which were much lower relative to that for soothing music. Only the demand for the sound of birdsong was slightly higher relative to that for other natural sounds.

Regarding sounds to abate, the most common types of sounds that the elderly wished to abate were the sound of people talking and other noises, with proportions of participants of approximately $25 \%$. However, the proportions of elderly people who wished to abate sounds related to music or activity were lower than $10 \%$, suggesting that although activityrelated sounds were rather loud sometimes, the interviewees were more tolerant of these sounds than they were of the sound of people talking or other noises.

\subsection{Effect of activity type on acoustic demands}

The results of chi-square correlation analysis performed to clarify relationships between specific activities and individual acoustic demands showed that most of the significantly correlated results involved abatement-related acoustic demands, suggesting that involvement in activities could engender demands for the abatement of sounds. For example, playing or watching Chinese chess was significantly correlated with the abatement of musical sounds $\left(\chi^{2}=6.02, p<.05\right)$ and abatement of the noise made during ball games $\left(\chi^{2}=4.97, p<.01\right)$. Playing or watching table tennis was significantly correlated with the abatement of the sound of people talking $\left(\chi^{2}=6.53, p<.01\right)$ and abatement of other noises $\left(\chi^{2}=6.05\right.$, $p<.01)$. However, only sitting still was significantly correlated with both adding and the abatement of certain sounds, which were adding the sound of birdsong $\left(\chi^{2}=5.64, p<.05\right)$, adding the sound of rustling trees $\left(\chi^{2}=4.05, p<.05\right)$, abatement of the sound of people talking $\left(\chi^{2}=7.93, p<.01\right)$, and no need to abate any sound $\left(\chi^{2}=7.92, p<.01\right)$.

In addition to the results of the correlation analysis, Fig. 2 depicts the percentage and average level for each acoustic demand during various activities, clarifying the differences between various activity groups. The results showed that activities related to table tennis, billiards, and sitting still could engender stronger demands for the addition of soothing music to an above-average level. Aside from soothing music, activities related to table tennis and sitting showed an increase in demands for four categories of natural sounds, suggesting that during these two activities, adding a mixture of soothing music and natural sounds could provide a positive acoustic environment. Another interesting finding was that, although the demand for stimulating music was much lower relative to that for soothing music in the overall analysis, it was more welcome in chatting and music-related activity categories than it was in others, reaching the level of the second most commonly demanded noise.

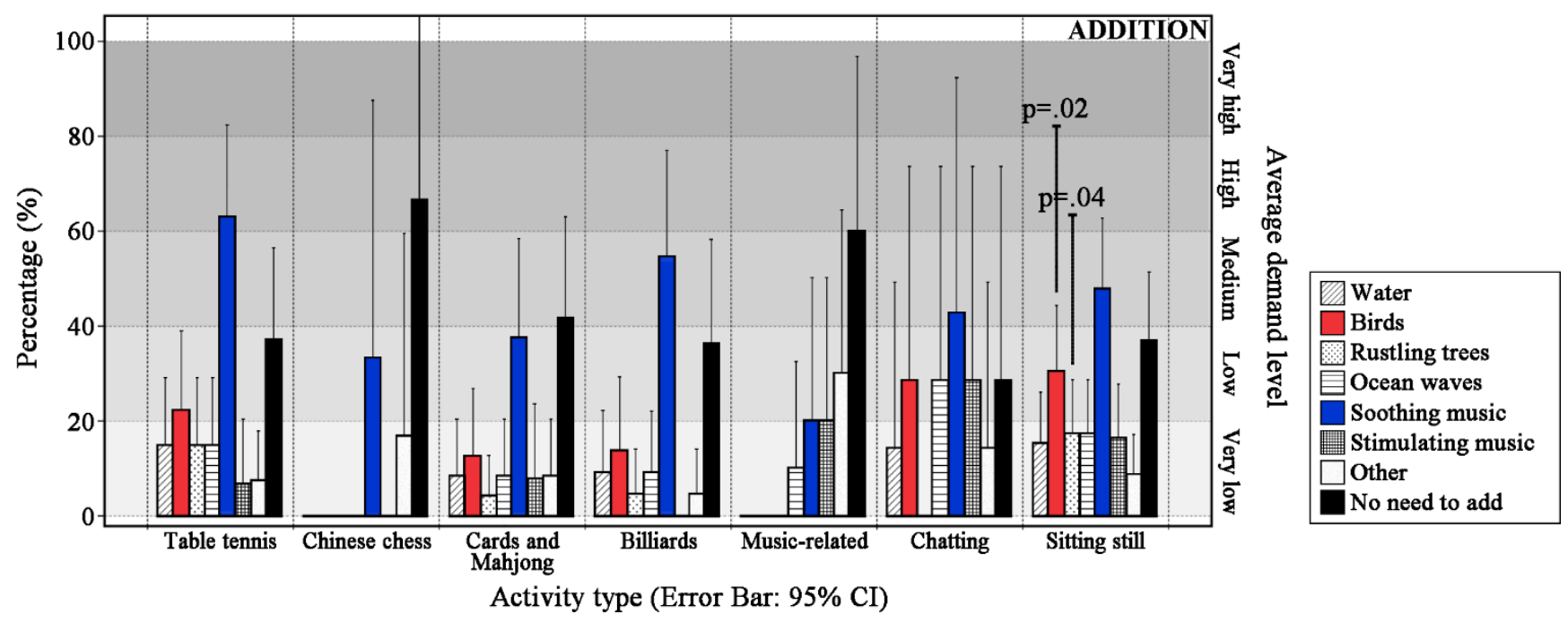

(a) 


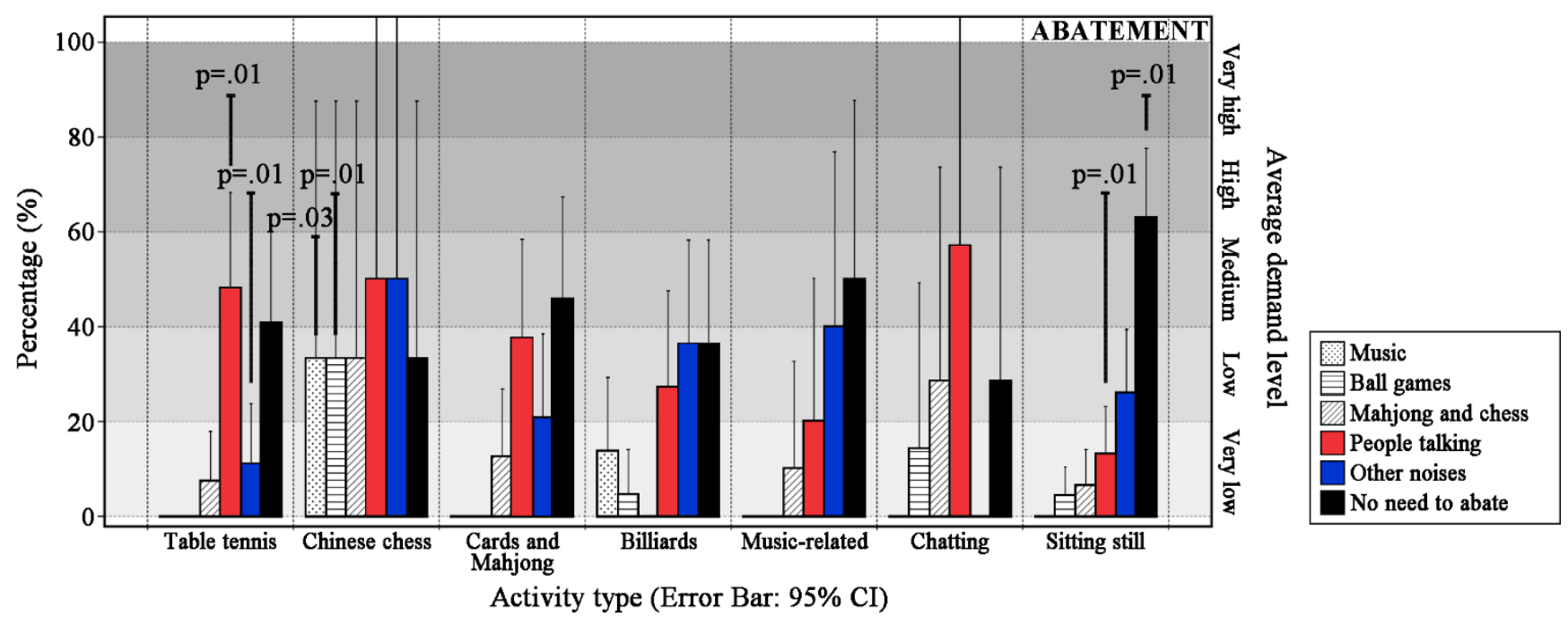

(b)

Fig. 2. The percentages and average demand levels for individual acoustic demands during different types of activities. (a) addition-related acoustic demands; (b) abatement-related acoustic demands. The results are indicated in blue, black, and red for the top three acoustic demands. Significance values for correlation analysis were provided as well.

Chinese chess was identified as a rather unique activity, as there were few demands to add any sounds, but there were demands for the abatement of all types of sound, even soothing music. The interviews with Chinese chess players suggested that playing Chinese chess requires a highly focused state, and relative to other participants, the elderly people who were playing Chinese chess were more likely to be bad tempered and refuse to be interviewed, even if they were merely watching, which resulted in a rather small sample size and large range of error. However, the confidence level did not affect the reliability of the result, as semi-structured interviews were conducted in the study. Some interviewees described this phenomenon as follows: 'Playing Chinese chess requires an absolutely quiet environment'; 'Don't talk to me when I am in the middle of a game, I don't want to hear anything'; 'There is no need to add any sound, I would like to shut down all the noises and voices if possible'.

Furthermore, compared to the previously-discussed activities, which require less speech, activities involving more speech (e.g. table tennis, playing cards, Mahjong, and chatting) tended to engender a greater demand for sound abatement of people talking compared to other ambient noises, and vice versa. This phenomenon could be related to the masking effect observed in previous research: if there is a single interfering sound, the masking effect of modulated noise is stronger relative to that of speech-based sounds. In contrast, if multiple sources of interference are present, the masking effect of speech-based sounds becomes stronger relative to that of modulated noise [33]. Interestingly, elderly people who were chatting exhibited low tolerance of the sound of other people talking, suggesting that rest areas in which the elderly rest and chat should be separated appropriately and that the interference of other chatting activities should be reduced to a minimum when designing facilities for the elderly.

\subsection{Effect of objective environment on acoustic demands}

\subsubsection{Number of people in a room}

The results of the partial correlation analysis showed a significant main effect of the number of people in a room on the demands for the abatement of the sound of people talking $(r=.33, p<.001)$ and no need to abate any sound $(r=-.26$, $p<.001)$. Fig. 3 presents the relationships between the number of people in a room and these two acoustic demands, with quadratic regression and corresponding correlation coefficients. The regression results for the abatement of the sound of people talking $\left(R^{2}=.49\right)$ and no need to abate any sound $\left(R^{2}=.46\right)$ were significant but the associations were not particularly strong. The acoustic demand for the abatement of the sound of people talking increased rapidly and then gradually slowed as the number of people increased, with a curved variation trend; however, the regression equation for the acoustic demand 
named 'no need to abate' was almost linear. In particular, as the number of people in a room increased, elderly people were more likely to demand the abatement of some sounds in the environment.

Another interesting finding (Fig. 3) was that two reference lines separated the dots into four quadrants, and most circular dots were scattered in Quadrants I and III, while the triangles were scattered mainly in Quadrants II and IV. Thus, 12 people seemed to reach the boundary between acceptable and unacceptable acoustic environments, as the proportion of demands for the abatement of the sound of people talking exceeded that for no need to abate any sounds. When the number of people in a room reached 12 , the proportion of elderly people who wished to abate some sounds would rapidly exceed $40 \%$, with this proportion of participants demanding the abatement of the sound of people talking, indicating that upper limits for the number of people in a room should be considered when designing indoor environments for the elderly.

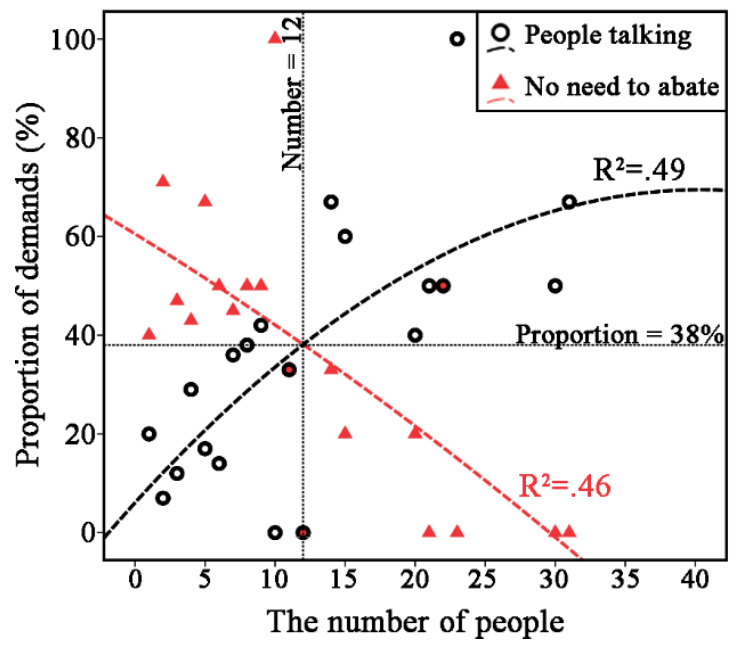

Fig. 3. The proportion of acoustic demands as a function of the number of people in a room. The averaged values of the demand ratios are plotted with circular dots and triangles, which represent the abatement of the sound of people talking and 'no need to abate', respectively. Quadratic regression curves are drawn with dotted lines.

\subsubsection{SPL (LAeq vs. LAmax)}

The results of the analysis of correlations between SPL and individual acoustic demands, with activity type, number of people, and occupation type as control variables for LAeq and activity type and number of people as control variables for LAmax, showed that LAeq was significantly correlated with three individual acoustic demands, including the addition of rustling trees $(r=-.16, p<.05)$ and the abatement of the noise made during ball games $(r=.19, p<.05)$ and the sound of people talking $(r=.17, p<.05)$. However, LAmax was significantly correlated only with stimulating music $(r=.19, p$ $<.05)$, indicating that LAeq exerted a stronger influence on acoustic demands, relative to that exerted by LAmax, in an indoor environment.

In addition, as shown in Fig. 4, as the value of LAeq increased, the polylines of four natural sounds became more similar, and the proportion of elderly people who expressed a demand for natural sounds reduced slightly if the fluctuations of the lines were ignored. It should be noted that the results regarding LAeq were analysed based on a range of SPL rather than specific values, as the proportions related to these individual acoustic demands remained the same within a range of $3 \mathrm{~dB}$ and changed at approximately $3 \mathrm{~dB}$.

However, some patterns that were observed were more interesting than linear relationships, as shown in Table 5. It is interesting to note that certain acoustic demands appeared within certain ranges of LAeq. When the room was quiet (e.g. LAeq $\leq 57 \mathrm{~dB}$ ), the addition of natural sounds and soothing music and abatement of other noises were demanded; however, when the room was neither quiet nor noisy (e.g. LAeq between 57 and $69 \mathrm{~dB}$ ), only the addition of soothing music was demanded, with the exception of the LAeq range of 63 to $66 \mathrm{~dB}$, within which a preference for avoiding changes to any sound, even soothing music, was observed, suggesting that the range of 63 to $66 \mathrm{~dB}$ could be a satisfactory LAeq range in indoor environments. Moreover, when the room was rather noisy (e.g. LAeq $>69 \mathrm{~dB}$ ), the demand for the abatement of 
the sound of people talking and addition of soothing music increased significantly. Meanwhile, 'no need to add' was also a popular option, possibly because it was too noisy to add further sounds with that level of sound pressure.

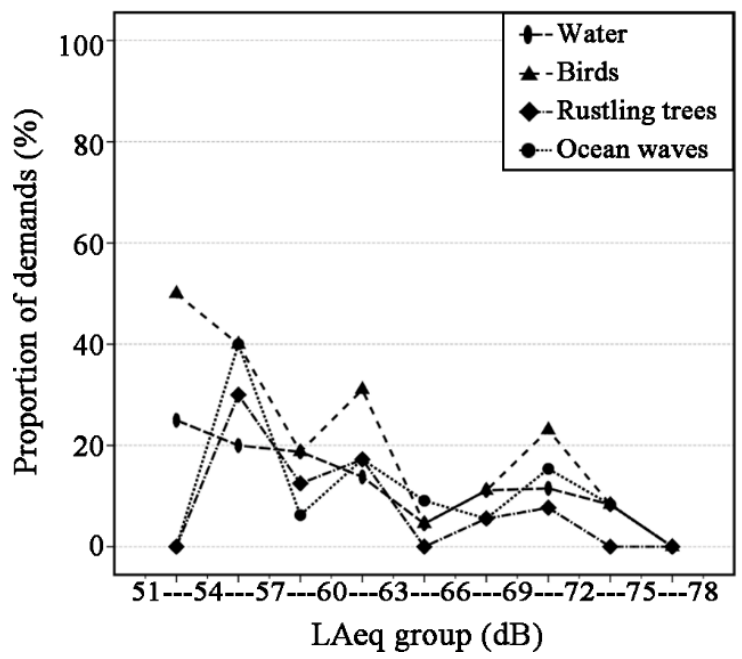

Fig. 4. Scatter-plot of the demand proportion for the addition of four types of natural sounds as a function of the LAeq group, with polylines to show the trend of fluctuations.

Table 5

Relationships between the LAeq group (dB) and individual acoustic demands.

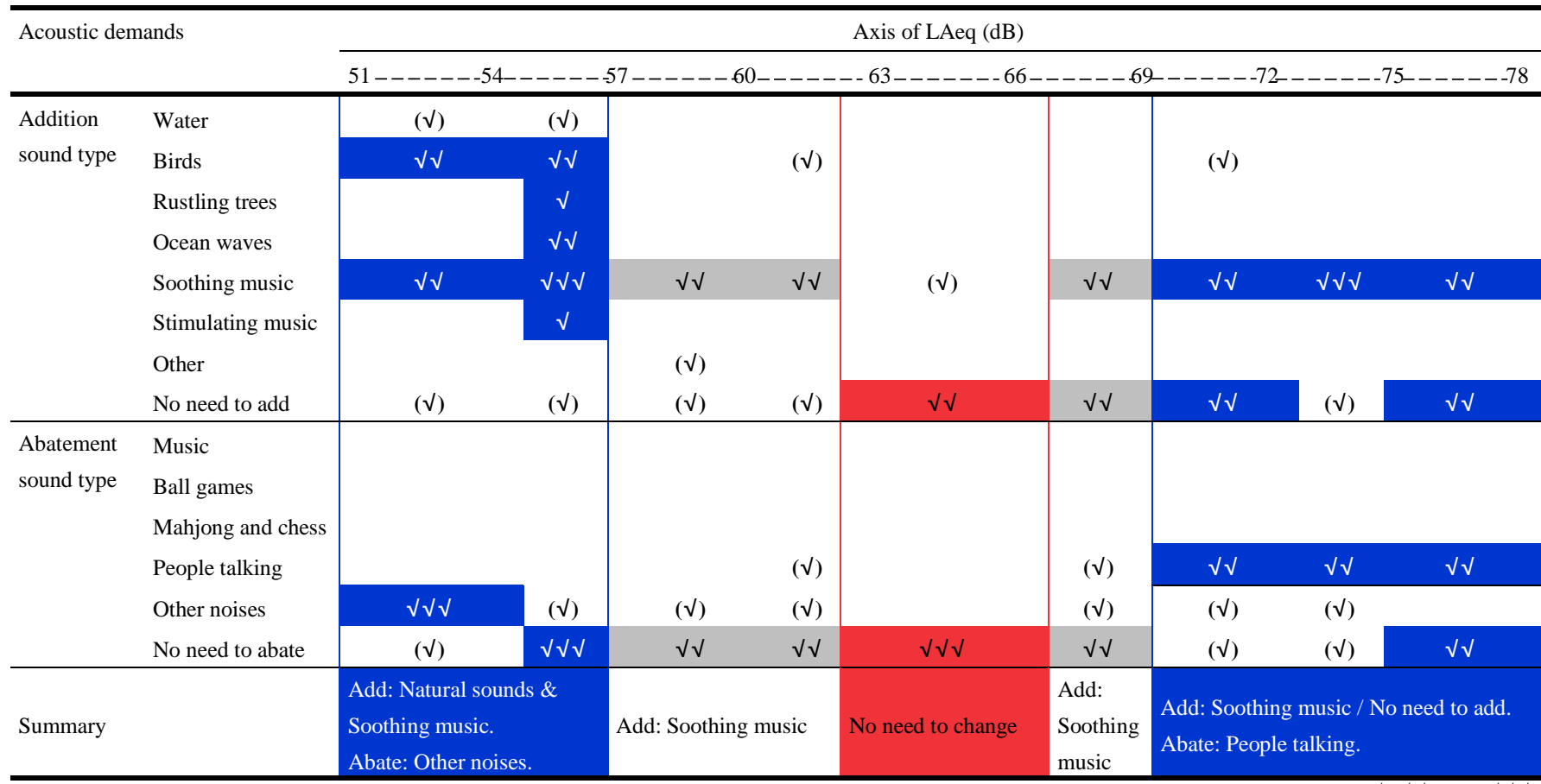

Table 5 shows the relationships between the LAeq group $(\mathrm{dB})$ and individual acoustic demands. The results are marked with $\sqrt{ }$, $\sqrt{ }$, and $\sqrt{ } \sqrt{ }$ for the proportion of demands of $20 \%-40 \%, 40 \%-60 \%,>60 \%$, respectively. The ones larger than $20 \%$-however lower in relation to that of other acoustic demands - are marked with $(\sqrt{ })$, while other relatively important ones are filled in with colours. Different colours are used to distinguish the summary groups.

\subsection{Effect of demographic factors on acoustic demands}

The results of chi-square correlation analysis and independent samples t-test examining the relationships between acoustic demands and demographic factors (i.e. age, sex, and occupation type) are shown in Table 6. The results regarding sex and occupation type were similar using two different methods: mean differences (t-test), and Goodman \& Kruskal tauy PRE. Moreover, these three demographic factors were all significantly correlated with certain abatement-related acoustic demands including the abatement of the sound of people talking, the abatement of other noises, and no need to abate. Age 
was also significantly correlated with stimulating music $\left(\chi^{2}=6.09, p<.05\right)$. Another notable result was that sex was the only factor that exerted a significant effect on acoustic demands on natural sound categories including water $(M D=0.12$, $p<.05)$, birdsong $(M D=0.15, p<.01)$, and rustling trees $(M D=0.11, p<.05)$.

\section{Table 6}

Chi-square correlation analysis of acoustic demands and demographic factors.

\begin{tabular}{|c|c|c|c|c|c|c|}
\hline \multirow{4}{*}{$\begin{array}{l}\text { Addition } \\
\text { sound type }\end{array}$} & \multirow[b]{3}{*}{ Water } & \multirow{2}{*}{$\begin{array}{l}\text { Age group } \\
\text { Chi-square } \\
\text { correlation }\left(\chi^{2}\right) \\
\text { /Significance }\end{array}$} & \multicolumn{2}{|l|}{ Sex (women - men) } & \multicolumn{2}{|c|}{ Occupation type (mental - physical) } \\
\hline & & & $\begin{array}{l}\text { Mean difference }(M D) \\
\text { /Significance }\end{array}$ & $\begin{array}{l}\text { Goodman \& Kruskal } \\
\text { tau-y PRE }(\%) \\
\text { /Significance }\end{array}$ & $\begin{array}{l}\text { Mean difference }(M D) \\
\text { /Significance }\end{array}$ & $\begin{array}{l}\text { Goodman \& Kruskal } \\
\text { tau-y PRE }(\%) \\
\text { /Significance }\end{array}$ \\
\hline & & $0.09 / 1.00$ & $.12 / .02$ & $3.8 / .02$ & $.00 / .98$ & $0.0 / .98$ \\
\hline & Birds & $0.55 / .76$ & $.15 / .02$ & 3.8/.02 $\quad(*)$ & $-.03 / .65$ & $0.1 / .65$ \\
\hline & Rustling trees & $1.56 / .51$ & $.11 / .02$ & 3.6/.02 $\quad(*)$ & $.04 / .48$ & $0.3 / .48$ \\
\hline & Ocean waves & $2.97 / .23$ & $.06 / .28$ & $0.8 / .28$ & $.02 / .73$ & $0.1 / .73$ \\
\hline & Soothing music & $2.58 / .28$ & $-.00 / .99$ & $0.0 / .99$ & $.15 / .09$ & $1.9 / .09$ \\
\hline & Stimulating music & $6.09 / .04$ & $.05 / .37$ & $0.7 / .37$ & $-.06 / .38$ & $0.7 / .38$ \\
\hline & Other & $4.23 / .12$ & $.02 / .71$ & $0.1 / .70$ & $-.08 / .19$ & $1.5 / .13$ \\
\hline & No need to add & $3.41 / .18$ & $.01 / .92$ & $0.0 / .92$ & $-.08 / .37$ & $0.6 / .37$ \\
\hline \multirow{5}{*}{$\begin{array}{l}\text { Abatement } \\
\text { sound type }\end{array}$} & Music & $1.69 / .44$ & $.00 / .94$ & $0.0 / .94$ & $.00 / .95$ & $0.0 / .95$ \\
\hline & Mahjong and Chess & $1.35 / .52$ & $-.04 / .44$ & $0.4 / .44$ & $.02 / .71$ & $0.1 / .71$ \\
\hline & People talking & 10.54/.01 (**) & $-.15 / .04$ & $2.9 / .04$ & $.14 / .07$ & $2.0 / .09$ \\
\hline & Other noises & $0.81 / .67$ & $-.01 / .87$ & $0.0 / .87$ & $.15 / .04$ & $2.4 / .06$ \\
\hline & No need to abate & $8.06 / .02$ & $.15 / .06$ & $2.4 / .06$ & $-.27 / .00$ & $6.3 / .00$ \\
\hline
\end{tabular}

Table 6 shows the Chi-square correlation results for associations between age and individual acoustic demands, mean differences (t-test) / Goodman \& Kruskal tau-y PRE (\%) of individual acoustic demands between women and men, and mean differences (t-test) / Goodman \& Kruskal tau-y PRE (\%) for individual acoustic demands between mental work type and physical work type, with significance levels (twotailed). ${ }^{\text {a }}$

$* p<.05$

$* * p<.01$

${ }^{\text {a }}$ Significant results are highlighted in bold print.

Fig. 5(a) shows the results for individual acoustic demands as a function of age. It is interesting to note that the 7080 year age range was a turning point for acoustic demands regarding the addition of sounds. Relative to other age groups, elderly people in this age group showed the lowest demand for natural and musical sounds, with the exception of the sound of birdsong, and the highest demand for no addition of further sounds. However, this tendency was not observed for abatement-related acoustic demands. Regarding the abatement sounds, older age was associated with higher tolerance for speech sounds and greater demand for no sound abatement.

Unlike in previous studies, in which the effects of sex on sound annoyance and acoustic comfort evaluations were non-significant, sex differences in acoustic demands were observed in the current study. The results showed that differences in acoustic demands between men and women were significant $(p<.05)$. As shown in Fig. 5(b), women tended to be more likely to choose to add natural sounds relative to men, and the differences in the proportions of men and women who made such demands were between $10 \%$ and $15 \%$, with the exception of that for ocean waves, for which there was no significant sex difference. Concerning abatement sounds, women exhibited higher tolerance for speech-related sounds and less demand for the abatement of sounds, relative to men.

Between mental and physical workers, differences in acoustic demands were significant only for the abatement of other noises $(p<.05)$ and 'no need to abate' $(p<.001)$, indicating that interviewees who had engaged mainly in physical 

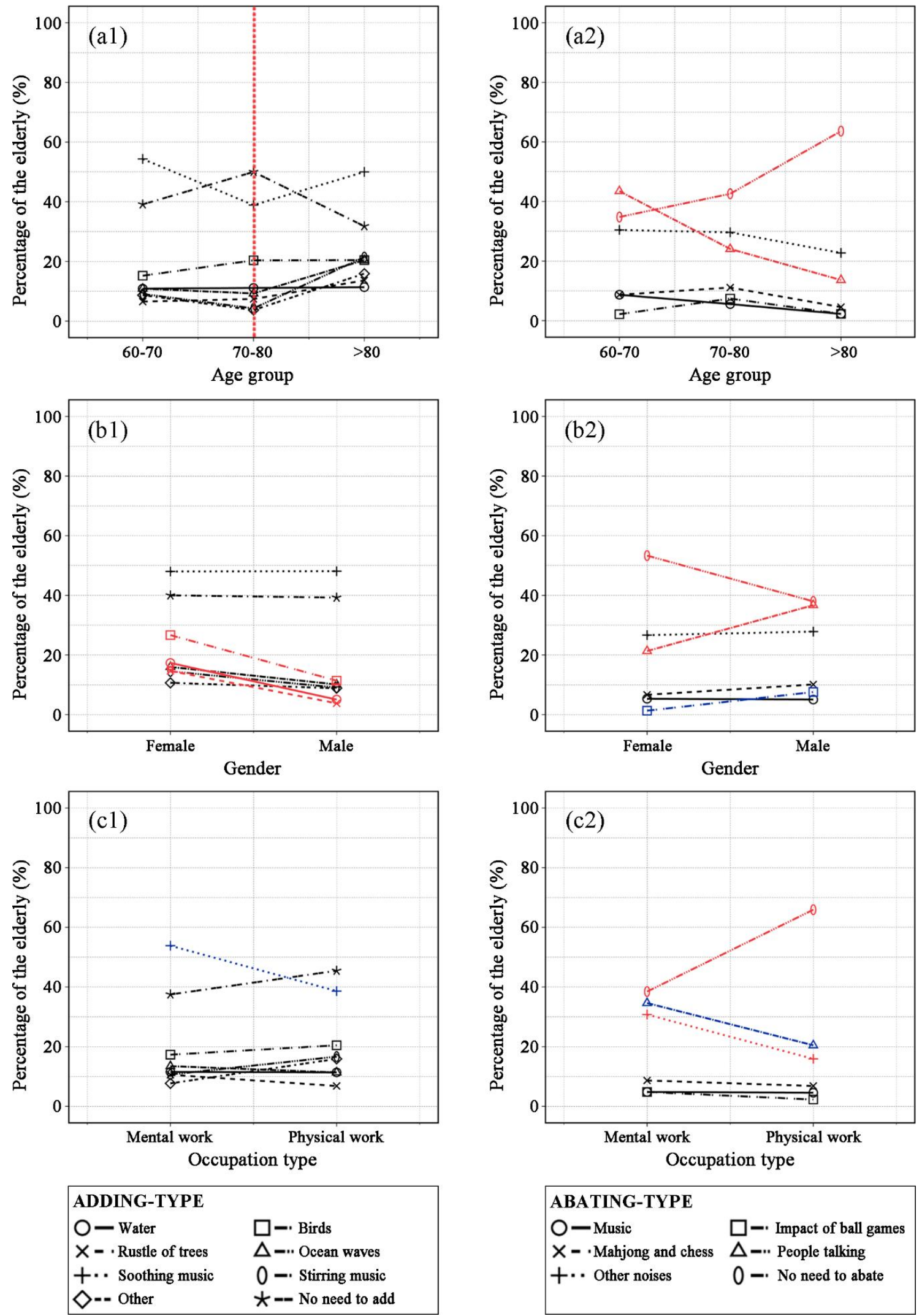

Fig. 5. The percentages of elderly people's acoustic demands according to the addition (on the left) and abatement (on the right) sound types as a function of three demographic factors. (a) age group (60-70, 70-80, and >80), with a reference line in red at the 70-80 age group; (b) sex; and (c) occupation type (mental work and physical work). The lines indicated in red represents the significant results, whereas the lines in blue represents the results that were approaching significance.

work tended to be more tolerant of all the sounds in the environment, while those who had engaged mainly in mental work 
tended to express more demands for the abatement of other noises, and the differences in proportions of participants who expressed these demands were $27 \%$ and $15 \%$, respectively. Furthermore, one possible reason for the observed differences in occupation type could be educational background, as Yu and Kang showed that people with higher educational levels showed lower noise tolerance in open spaces in urban areas [13]. The former working environment could have been another reason for this finding, as physical workers are generally exposed to higher sound levels and noisier environments; therefore, they may have become accustomed to loud noises.

Other than the results with significant $\mathrm{p}$ values, it should be noted that in Table 6, some $\mathrm{p}$ values ranged between .05 and .10 , suggesting that although these results were non-significant, they approached significance. For example, the abatement of the noise made during ball games was demanded by men more frequently than it was by women. Furthermore, retired mental workers were more likely to demand the addition of soothing music and abatement of the sound of people talking, relative to retired physical workers, and the differences in proportions of these demands were approximately $15 \%$.

\section{Discussion}

4.1 Relationships between sound preference and acoustic demands

In the field of soundscapes, many dimensions of sound preference have been studied [13-15, 34-36]. The influencing factors that exerted significant effects on the sound preference evaluation or at least for certain sound types have been systematically examined, considering social, demographical, physical, behavioural and psychological facets [13], which is similar to the results of acoustic demands in this study, providing noted bases for soundscape design. Yet individuals' sound preferences could also affect their acoustic demands, as demanding the sounds that one prefers is reasonable, making sound preferences not only a group of soundscape design indexes but also a facet of influencing factors of acoustic demands. Therefore, further research is necessary to verify whether sound preferences could be used to predict acoustic demands.

Partial correlation analysis was performed to explore the relationships between preferences and acoustic demands for the same types of sound. Table 7 shows the correlations between individual sound preferences and acoustic demands, with age, sex, occupation type, LAeq, and LAmax as control variables, which suggested that these associations were significant for music sounds and human sounds, and non-significant for most natural sounds. However, only the demand for the sound of ocean waves was significantly positively related to preference for the sound.

Previous studies have shown that older people may be more appreciative of natural sounds over teenagers [10], suggesting that natural sounds could be provided to the elderly when designing a soundscape. However, the results from this study suggested that the proportions of elderly people who wished to add natural sounds were lower than $20 \%$, which is inconsistent with the extent to which people enjoy natural sounds.

However, another interesting finding regarding demands for natural sounds was noticed when examining the relationship between the preference for overall acoustic environment and acoustic demands, as demonstrated in Table 8 . The results of partial correlation analysis (with the number of people as the control variable) showed that the preference for overall acoustic environment was strongly associated with the demands for the addition of natural sounds, with the exception of the sound of birdsong. Although correlation coefficients were not very high, suggesting that the reason why the interviewees did not express much demand for natural sounds could be that they disliked the overall acoustic environment.

In terms of influencing factors, such as gender and age, some differences in sound preference have been found, although they are less significant than those amongst age groups, and it is suggested that the differences between sounds may exceed gender differences [16]. Regarding this aspect, the findings of this study support the theory that males and females perceive sounds differently; however, for the elderly, these differences in acoustic demands were found to be more notable than amongst age groups.

Overall, the above analysis indicated that some relationships existed between individual sound preference and acoustic demands, which suggest that to some extent, what elderly people enjoy could affect decisions regarding what they desire when no other influencing factors are present. However, activity type and objective environment could change 
constantly; thus, using acoustic demands to guide the design of acoustic environments would be advisable.

Table 7

Correlation coefficients between individual sound preferences and corresponding acoustic demands.

\begin{tabular}{|c|c|c|c|c|c|c|c|c|c|}
\hline \multirow[t]{2}{*}{ Preferences } & \multicolumn{9}{|c|}{ Acoustic demands } \\
\hline & Water & Birds & Rustling trees & Ocean waves & $\begin{array}{l}\text { Soothing } \\
\text { music }\end{array}$ & $\begin{array}{l}\text { Stimulating } \\
\text { music }\end{array}$ & Ball games & People talking & $\begin{array}{l}\text { Mahjong } \\
\text { and chess }\end{array}$ \\
\hline Water & $0.10 / 0.31$ & $0.05 / 0.59$ & $0.06 / 0.54$ & $0.04 / 0.71$ & $-0.08 / 0.40$ & $-0.02 / 0.87$ & $0.09 / 0.36$ & $0.06 / 0.52$ & $0.07 / 0.50$ \\
\hline Birds & $0.15 / 0.13$ & $0.17 / 0.09$ & $0.10 / 0.31$ & $0.16 / 0.10$ & $-0.02 / 0.83$ & $0.01 / 0.93$ & $-0.10 / 0.30$ & $0.06 / 0.58$ & $0.04 / 0.68$ \\
\hline Rustling trees & $0.10 / 0.34$ & $0.08 / 0.45$ & $0.08 / 0.40$ & $0.02 / 0.85$ & $-0.01 / 0.91$ & $0.05 / 0.59$ & $-0.01 / 0.91$ & $0.06 / 0.58$ & $0.02 / 0.81$ \\
\hline Ocean waves & $0.16 / 0.11$ & $0.09 / 0.37$ & $0.03 / 0.77$ & $0.20 / 0.04 *$ & $-0.09 / 0.34$ & $0.09 / 0.39$ & $-0.12 / 0.24$ & $-0.03 / 0.74$ & $0.04 / 0.71$ \\
\hline Soothing music & $0.10 / 0.26$ & $-0.03 / 0.70$ & $0.11 / 0.21$ & $0.06 / 0.47$ & $0.30 / 0.00 * *$ & $0.23 / 0.02 *$ & $0.12 / 0.18$ & $0.01 / 0.87$ & $0.05 / 0.54$ \\
\hline Stimulating music & $0.10 / 0.32$ & $-0.01 / 0.94$ & $0.08 / 0.43$ & $0.16 / 0.12$ & $0.06 / 0.56$ & $0.33 / 0.00 * *$ & $-0.09 / 0.34$ & $0.07 / 0.51$ & $0.02 / 0.84$ \\
\hline Ball games & $0.19 / 0.03 *$ & $0.18 / 0.04 *$ & $0.10 / 0.24$ & $0.10 / 0.26$ & $0.00 / 0.96$ & $-0.07 / 0.45$ & $-0.24 / 0.01 * *$ & $-0.13 / 0.14$ & $-0.11 / 0.20$ \\
\hline People talking & $-0.02 / 0.85$ & $-0.02 / 0.83$ & $-0.07 / 0.44$ & $0.08 / 0.37$ & $-0.17 / 0.05^{*}$ & $0.03 / 0.73$ & $0.04 / 0.66$ & $-0.36 / 0.00 * *$ & $-0.10 / 0.27$ \\
\hline Mahjong and chess & $0.01 / 0.90$ & $0.11 / 0.22$ & $-0.09 / 0.33$ & $0.01 / 0.87$ & $-0.04 / 0.66$ & $0.03 / 0.73$ & $0.03 / 0.75$ & $-0.07 / 0.41$ & $0.07 / 0.42$ \\
\hline
\end{tabular}

Significance level (two-tailed). ${ }^{\mathrm{a}}$

$* p<.05$

$* * p<.01$

a Significant results are highlighted in bold print.

Table 8

Correlation coefficients between the preference for overall acoustic environment and individual acoustic demands.

\begin{tabular}{|c|c|c|c|c|c|c|c|c|c|c|c|c|c|c|c|}
\hline & & \multicolumn{8}{|c|}{ Addition sound type } & \multicolumn{6}{|c|}{ Abatement sound type } \\
\hline & & Water & Birds & $\begin{array}{l}\text { Rustling } \\
\text { trees }\end{array}$ & $\begin{array}{l}\text { Ocean } \\
\text { waves }\end{array}$ & $\begin{array}{l}\text { Soothing } \\
\text { music }\end{array}$ & $\begin{array}{l}\text { Stimulating } \\
\text { music }\end{array}$ & Other & $\begin{array}{l}\text { No need } \\
\text { to add }\end{array}$ & Music & $\begin{array}{l}\text { Ball } \\
\text { games }\end{array}$ & $\begin{array}{l}\text { Mahjong } \\
\text { and chess }\end{array}$ & $\begin{array}{l}\text { People } \\
\text { talking }\end{array}$ & $\begin{array}{l}\text { Other } \\
\text { noises }\end{array}$ & $\begin{array}{l}\text { No } \\
\text { need to } \\
\text { abate }\end{array}$ \\
\hline $\begin{array}{l}\text { Preference for } \\
\text { overall }\end{array}$ & Correlation & $0.17 *$ & 0.14 & $0.19 *$ & $0.21 * *$ & -0.05 & -0.03 & -0.05 & 0.05 & -0.06 & -0.14 & $-0.17 *$ & -0.12 & -0.05 & 0.15 \\
\hline $\begin{array}{l}\text { acoustic } \\
\text { environment }\end{array}$ & Significance & 0.04 & 0.09 & 0.02 & 0.01 & 0.57 & 0.75 & 0.56 & 0.51 & 0.49 & 0.09 & 0.04 & 0.14 & 0.53 & 0.07 \\
\hline \multicolumn{16}{|c|}{ Significance levels (two-tailed). ${ }^{a}$} \\
\hline \multicolumn{16}{|c|}{$* p<.05$} \\
\hline
\end{tabular}

\subsection{Comparison of all influencing factors}

The results of this study showed that more than half of the elderly individuals preferred to add soothing music over other sounds, suggesting that in the spaces where elderly people carry out daily activities, soothing music could be played via electro-acoustic system. Yet the selection of specific musical style and the appropriate interval between two pieces of music still require further investigation. Concerning the sounds of people talking that the elderly wanted to abate most, active noise reduction approaches could be adopted [37]. Moreover, since previous studies found that music sounds could mask ambient noises in urban squares, thereby reducing the evaluation of sound levels [13]; hence, provided with the sounds that the elderly preferred to add, the demands for abating the sound of people talking and other noises, in the meantime, might decrease. Yet further research is required.

However, although soothing music was the only sound with greater demands than 'no need to add' and 'no need to abate' amongst the elderly, it only represented an overall statistical probability, and did not mean that other acoustic 
demands are non-significant in certain circumstances, particularly for rooms with different functions and various objective environment. For example the demand to add natural sounds, which was strongly influenced by sex, preference for overall acoustic environment, and individual sound preference. It indicated that although the demand for natural sounds was not high in the study, it could be explained by the sex ratio and preference for overall acoustic environment. In other words, if there were more elderly women living in a care facility or the acoustic environment could have been improved, the demand for the addition of natural sounds might not have been as low as that observed.

Of all the influencing factors along with sound preference indices examined in the study, the top three factors that exerted greater effects based on the number of acoustic demands significantly affected are activity type, individual sound preference, and preference for overall acoustic environment, as shown in Table 9. Furthermore, activity type influenced most of the abatement-related acoustic demands, while individual sound preference covered most of the addition demands, suggesting that activity type generally underlies the decision as to which sound to abate, while individual sound preference generally underlies the decision as to which sound to add.

In addition, as mentioned in Section 2.5, there were significant differences in acoustic demands for the addition of the sound of ocean waves, the abatement of the sound of people talking, and 'no need to abate' between the three facility types. Table 9 could provide some insight into these differences, as the demand for the sound of ocean waves significantly correlated with sound preference indices, suggesting that the noted differences influenced by sound preference or former experience of sounds [35]. Concerning abatement-related acoustic demands, they were significantly related to multiple influencing factors, suggesting that the differences between these factors could exceed facility-type differences. However, these hypotheses require further investigation.

Table 9

Relationship between all influencing factors and individual acoustic demands.

\begin{tabular}{|c|c|c|c|c|c|c|c|c|c|c|c|c|c|c|}
\hline \multirow[b]{3}{*}{ Influencing factor } & \multicolumn{8}{|c|}{ Addition sound type } & \multicolumn{6}{|c|}{ Abatement sound type } \\
\hline & \multicolumn{4}{|c|}{ Natural } & \multicolumn{2}{|c|}{ Musical } & \multicolumn{2}{|c|}{ Others } & \multicolumn{3}{|c|}{ Activity } & \multirow{2}{*}{ 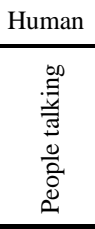 } & \multicolumn{2}{|c|}{ Others } \\
\hline & 离 & : & 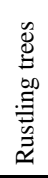 & 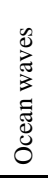 & 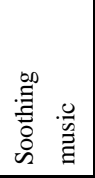 & 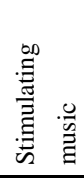 & $\begin{array}{l}\bar{\Xi} \\
\overline{0}\end{array}$ & 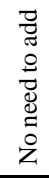 & $\sum_{\substack{n \\
\frac{n}{n}}}^{2}$ & 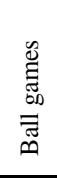 & 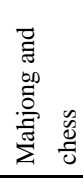 & & 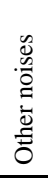 & 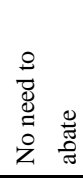 \\
\hline Activity type & & & & & & & & & & & & & & \\
\hline $\begin{array}{l}\text { Individual sound } \\
\text { preference }\end{array}$ & & & & & & & & & & & & & & \\
\hline $\begin{array}{l}\text { Preference for overal } \\
\text { acoustic environmen }\end{array}$ & & & & & & & & & & & & & & \\
\hline Sex & & & & & & & & & & & & & & \\
\hline Age & & & & & & & & & & & & & & \\
\hline LAeq (dB) & & & & & & & & & & & & & & \\
\hline $\begin{array}{l}\text { The Number of peop } \\
\text { in a room }\end{array}$ & & & & & & & & & & & & & & \\
\hline $\begin{array}{l}\text { Occupation type } \\
\text { (Mental vs. Physical) }\end{array}$ & & & & & & & & & & & & & & \\
\hline LAmax $(\mathrm{dB})$ & & & & & & & & & & & & & & \\
\hline
\end{tabular}

Table 9 showed the relationship between all influencing factors and individual acoustic demands sorted by the number of acoustic demands significantly affected. The results with significance values of $\mathrm{p}<.01$ and $\mathrm{p}<.05$ were filled in dark and light grey, respectively.

Moreover, some restrictions and explanations regarding the practical implications of two of the factors are also important to note. Firstly, in terms of activity type, the results could be applied to the estimation of the elderly individuals' acoustic demands according to the activities they were involved in, and for a room with single activity, these results could 
be extended to estimate the overall sound requirements of the room, but they are not applicable to a single space with multiple activities.

Secondly, is the number of people in a room, of which the emergence of the quadratic regression trends was based on the number of people of any room the interviewee was in, regardless of room size or capacity, which is similar to the findings of Aletta et al. [24]. They found that the level of activity of the people in living rooms affects the sound levels, regardless of the room acoustics conditions (i.e. volume of the room and reverberation time). The curve that shows the relationship between sound levels and the number of people also tends to rise rapidly and then flatten or decline. It, therefore, indicated that upper limits for the number of people in a room should be considered when designing indoor environments for the elderly, and an appropriate range of room size could be calculated based on this result together with the space required for certain activity.

\section{Conclusions}

This cross-sectional, semi-interviewed questionnaire survey explored the acoustic demands of the elderly and analysed the effects of activity type, objective environment, demographic factors, and sound preference in six selected facilities in China.

The results suggested that soothing music was the most commonly desired sound for addition to the environment, and natural sounds were not as strongly demanded as expected, although demand for birdsong was slightly higher relative to that for the sound of water, rustling trees, and ocean waves. Concerning the demand for the abatement of sounds, the most commonly unwanted sounds were those of people talking and other noises.

Regarding the effects of activity type, a few significant results were observed. Activities related to table tennis and Chinese chess exerted significant effects on the acoustic demand for abatement sounds, while sitting still showed significant effects on both addition-related and abatement-related acoustic demands. Activities related to Chinese chess were subject to the greatest disturbance from sound; therefore, a quiet environment was required for this activity. In contrast, when elderly people were sitting still, they showed high levels of acceptance of all types of sound in the environment, and there was no demand for the abatement of any sounds.

Regarding the effects of objective environment, the presence of $>12$ people in a room could cause a considerable increase in the demand for the abatement of sounds, particularly that of people talking. In contrast, LAeq exerted a stronger influence on acoustic demands relative to that exerted by LAmax. Moreover, both linear and transitional relationships were observed between individual acoustic demands and LAeq.

The analysis of demographic factors showed that elderly people's tolerance of the sound of people talking increased with age, and there were significant differences in addition-related acoustic demands between people aged 70 and 80 years, relative to younger or older age groups. Moreover, women were more likely to demand the addition of natural sounds and showed greater tolerance of the sound of people talking and the noise made during ball games relative to men. In terms of occupation type, elderly people who were engaged in mental work before retirement were more likely to demand the abatement of the sound of people talking and other noises relative to those who had been physical workers.

The results regarding relationships between acoustic demands and sound preference showed that although significant correlations were observed, elderly people's individual acoustic demands could not be predicted using only sound preference indices. In addition, elderly people's preference for the overall acoustic environment could affect their acoustic demand for the addition of natural sounds. Furthermore, the comparison of all the influencing factors indicated that activity type generally underlies the decision as to which sound to abate, while individual sound preference generally underlies the decision as to which sound to add.

Overall, the results of this study suggested that although most older people experience hearing loss, they exhibit the demand for sound, and a quiet living environment might be important but insufficient. In addition, it is necessary to consider the potential numbers of people in rooms and the appropriate acoustic demands, based on activity type and other influencing factors, when designing facilities for the elderly. 


\section{CRediT authorship contribution statement}

Luying Wang: Conceptualization, Methodology, Software, Validation, Formal analysis, Investigation, Resources, Data curation,Writing - original draft, Visualization, Project administration. Jian Kang: Writing - review \& editing, Supervision, Funding acquisition.

\section{Declaration of Competing Interest}

The authors declare that they have no known competing financial interests or personal relationships that could have appeared to influence the work reported in this paper.

\section{Acknowledgements}

This work was supported by the State Natural Science Foundation of China [grant number 51778169]. The authors are indebted to Yan Zhang for useful discussion, and to Zhongzhe $\mathrm{Li}, \mathrm{Xu}$ Zhang and the anonymous reviewers for their valuable comments.

\section{References}

[1] World Health Organization (WHO). China Country Assessment Report on Ageing and Health. Geneva: WHO Press, Switzerland, 2016.

[2] Gerven PWMV, Vos H, Boxtel MPJV, Janssen SA, Miedema HME. Annoyance from environmental noise across the lifespan. J Acoust Soc Am 2009; 126:187-194.

[3] Miller JD. Effects of noise on people. J Acoust Soc Am 1974; 56:729.

[4] Li-Korotky HS. Age-related hearing loss: quality of care for quality of life. Gerontol 2012; 52:265-71.

[5] Kim YH, Soeta Y. Effects of reverberation and spatial diffuseness on the speech intelligibility of public address sounds in subway platform for young and aged people. J Acoust Soc Am 2013; 133:3378.

[6] Wu YH, Bentler RA. Do older adults have social lifestyles that place fewer demands on hearing?. J Am Acad Audiol 2012; 23:697.

[7] Campos J, Ramkhalawansingh R, Pichora-Fuller MK. Hearing, self-motion perception, mobility, and aging. Hear Res 2018.

[8] Yu L, Kang J. Effects of social, demographical and behavioral factors on the sound level evaluation in urban open spaces. J Acoust Soc Am 2008; 123:772-783.

[9] Botteldooren D, Decloedt S, Bruyneel J, Pottie S. Characterization of quiet areas: Subjective evaluation and sound-level indices. J Acoust Soc Am 1999; 105:1377-1377.

[10] Yang W, Kang J. Acoustic comfort evaluation in urban open public spaces. Appl Acoust 2005; 66:211-229.

[11] Dokmeci PN, Yilmazer S. Relationships between measured levels and subjective ratings A case study of the food-court area in CEPA shopping center Ankara. Build Acoust 2012; 19:57-73.

[12] Meng Q, Kang J. Effect of sound-related activities on human behaviours and acoustic comfort in urban open spaces. Sci Total Environ 2016; 573:481-493.

[13] Yu L, Kang J. Factors influencing the sound preference in urban open spaces. Appl Acoust 2010; 71:622-633.

[14] Refat IM. Sound preferences of the dense urban environment: Soundscape of Cairo. Front Archit Res 2014; 3:55-68.

[15] Lee PJ, Hong JY, Jeon JY. Assessment of rural soundscapes with high-speed train noise. Sci Total Environ 2014; 482-483:432-439.

[16] Yang W, Kang J. Soundscape and Sound Preferences in Urban Squares: A Case Study in Sheffield. J Urban Des 2005; 10:61-80.

[17] Yang W, Kang J. Acoustic comfort and psychological adaptation as a guide for soundscape design in urban open public spaces. In: Proceedings of the 17th International Congress on Acoustics (ICA), 2001.

[18] Carles J, Bernáldez F, Lucio J. Audio-visual interactions and soundscape preferences. Landsc Res 1992; 17:52-56.

[19] Yu L. Soundscape evaluation and ANN modelling in urban open spaces, PhD dissertation, University of Sheffield, UK, 2009.

[20] De Ruiter E. Noise control in the compact city. In: Proceedings of the 7th international congress on sound and vibration, 2000. p. 242126.

[21] Raimbault M, Lavandier C, Bérengier M. Ambient sound assessment of urban environments: field studies in two French cities. Appl Acoust 2003; 64:1241-1256. 
[22] Meng Q, Zhang S, Kang J. Effects of typical dining styles on conversation behaviours and acoustic perception in restaurants in China. Build Environ 2017; 121:148-57.

[23] Meng Q, Sun Y, Kang J. Effect of temporary open-air markets on the sound environment and acoustic perception based on the crowd density characteristics. Sci Total Environ 2017; 601-602:1488-95.

[24] Aletta F, Botteldooren D, Thomas P, Mynsbrugge TV, Vriendt PD, de Velde DV, et al. Monitoring Sound Levels and Soundscape Quality in the Living Rooms of Nursing Homes: A Case Study in Flanders (Belgium). Appl Sci 2017; 7:874.

[25] Ren X, Kang J, Jin H. Residents' sound preference of rural soundscape in China. J Acoust Soc Am 2015; 138:1750-1750.

[26] Han MH, Joo MK, Oh YK. Residential and Acoustic Environments Perceived by Residents of Regional Cities in Korea: A Case Study of Mokpo City. Indoor Built Environ 2010; 19:102-113.

[27] Peng J, Zeng Y, Zhao L, Zeng J. An investigation of acoustical environments in the elderly care facilities. Appl Acoust 2018; 137:45-50.

[28] Li Z, Kang J. Sensitivity analysis of changes in human physiological indicators observed in soundscapes. Landsc Urban Plan 2019.

[29] Xu D, Yu L, Kang J. Identifying Sound Sources in terms of Urban Environmental Parameters. In: INTER-NOISE and NOISE-CON Congress and Conference Proceedings, InterNoise18, 2018. p. 2587-95.

[30] Ou D, Mak CM, Pan S. A method for assessing soundscape in urban parks based on the service quality measurement models. Appl Acoust 2017; 127:184-193.

[31] Huo X, Ren J. On Maintenance and Expansion of Musical Hearing Ability of Old People. J Xinghai Conserv Music 2010; 4:81-85. [in Chinese].

[32] Huo X. Auditory aesthetic preferences of the elderly -- taking auditory dependence, sound type, volume, speed and timbre preferences as examples. J Xinghai Conserv Music 2016; 3:98-106. [in Chinese].

[33] Hawley ML, Litovsky RY, Culling JF. The benefit of binaural hearing in a cocktail party: Effect of location and type of interferer. J Acoust Soc Am 2004; 115:833-843.

[34] Zhang D, Zhang M, Liu D, Kang J. Sounds and sound preferences in Han Buddhist temples. Build Environ 2018; 142:58-69.

[35] Ren X, Kang J. Comparative study on sound preferences between Chinese and English rural tourists. In: Proceedings of the 24th International Congress on Sound and Vibration, 2017.

[36] Yu L, Kang J. Using ANN to study sound preference evaluation in urban open spaces. J Environ Eng Landsc Manag 2015; 23:163-171.

[37] Utyuzhnikov S V. A practical algorithm for real-time active sound control with preservation of interior sound. Comput \& Fluids 2017; 157:175-181. 